\title{
The sentience argument for experientialism about welfare
}

\author{
Willem van der Deijl ${ }^{1}$
}

\begin{abstract}
Can a person's degree of wellbeing be affected by things that do not enter her experience? Experientialists deny that it can, extra-experientialists affirm it. The debate between these two positions has focused on an argument against experientialism - the experience machine objection-but few arguments exist for it. I present an argument for experientialism. It builds on the claim that theories of wellbeing should not only state what constitutes wellbeing, but also which entities are welfare subjects. Moreover, the claims it makes about these two issues should have a certain coherence with each other. I argue that if we accept a particular plausible answer to the second question-namely that all and only sentient beings are welfare subjects-extra-experientialist theories face a problem of coherence. While this problem can typically be solved, doing so will involve steps that are unattractive. On experientialist theories, on the other hand, the answer to these questions cohere perfectly.
\end{abstract}

Keywords Wellbeing · Experience requirement · Experientialism · Hedonism

\section{Experience: the requirement and the machine}

Can something that you do not experience affect your wellbeing, or welfare? ${ }^{1}$ Who does not feel aversion against the idea of their friends talking badly of them behind their backs, their partners cheating on them without them knowing, or living,

\footnotetext{
${ }^{1}$ I follow the philosophical literature in using these two concepts interchangeably.

Willem van der Deijl

wjavanderdeijl@gmail.com

1 Department of Philosophy, Tilburg university, Mauritsweg 56D, 3012JX Rotterdam, The Netherlands
} 
unbeknownst to ourselves, in a virtual reality while our real body sits helplessly in an artificial life-support machine? Nevertheless, do these things actually affect someone's wellbeing - that is, how good a person's life is for them-even if they in no way affect the experience a person is having? Theories of wellbeing are divided on the topic. Theories that accept that only what affects a person's experience can affect the degree of someone's wellbeing endorse the experience requirement. I will refer to theories that endorse the requirement as experientialist theories of wellbeing. ${ }^{2}$ Out of the common contemporary tripartite taxonomy of wellbeing (Parfit 1984), only hedonism - the view that the degree of someone's wellbeing is constituted only by pleasure and pain-unambivalently accepts it. Alternative theories tend to reject the requirement. Almost all accounts of wellbeing hold that experiential goods-such as pleasure-matter, or at the very least, can matter. Consequently, the view that wellbeing nevertheless need not abide by the experience requirement I call extra-experientialism.

Experientialism is highly controversial. One reason for this is that the idea suffered greatly from an objection based on a counterexample from Nozick (1974): the experience machine. This objection imagines an artificial machine that creates the most incredible virtual experiences for whoever sits in it, while in reality that person just sits passively in a chair in the machine. Would you plug in? Many would not. So, the argument goes, why not? If experientialism is correct, all that matters to wellbeing is experience. Not only are the experiences in the machine good, but, as Nozick frames it, they are great, much better than real lives! So, if virtual life is not the best life, experientialism is false. This argument has had much impact on the perceived plausibility of hedonism in specific, and experientialism in general. However, in recent years, a debate about the efficacy of the argument has resurfaced (see Weijers and Schouten 2013; Bramble 2016 for overviews). Experimental evidence on the causal influence of irrelevant factors to responses to the counterexample - such as status quo biases or moral considerations-have cast doubt on its argumentative efficacy (De Brigard 2010; Weijers 2014; cf. Rowland 2017; Lin 2016; see Hawkins 2015; see also Crisp 2006, 117-125 for a powerful defense of hedonism in light of the experience machine counterexample).

This article does not substantively engage with the debate about the efficacy of the experience machine objection. Rather, it accepts that the example provides a pro tanto argument against experientialism. Instead, I focus on a more elementary question: why is experientialism plausible in the first place? If the experience

\footnotetext{
${ }^{2}$ Experientialism is closely related to, but distinct from the concept of a mental-state accounts of wellbeing - the view that wellbeing consists in intrinsic properties of mental states. The category of mental states is potentially broader than the category of experiences. Arguably, subconscious states and emotional dispositions are mental states, but need not necessarily affect a person's experience (Haybron 2005; see also Sumner 1996, 29, ft.2). Moreover, the term experientialism is sometimes used in a narrower sense than the way that I use it here. Experientialism is sometimes defined as the view that the sole bearers of intrinsic value are experiences (e.g. Hawkins Hawkins 2015, 155). As an anonymous referee points out, there is space for theories that fit in the broad, but not this narrow definition of experientialism (Hawkins 2015, 163-164). The broad definition allows for welfare goods that are themselves non-experiential, but gain welfare value once they are experienced. For the purposes of this article, this distinction will not be relevant, and I will use the term in the broad sense.
} 
machine objection provides a pro tanto argument against it, are there any arguments for it? Surprisingly, arguments for experientialism have not received much attention (though Kagan 1992 comes close). ${ }^{3}$ In this article, I present an argument for experientialism. I first note that a theory of wellbeing should not only present an account of the constituents of wellbeing, but should also be able to say to which individuals we can ascribe levels of wellbeing, and to which entities the concept of wellbeing does not apply. In other words, they need to provide an account that demarcates welfare subjects from non-welfare subjects. The argument that I present builds on this and observes that if it comes to this question, the most plausible and intuitive account suggests that all and only sentient beings have wellbeing, a view I call welfare sentientism. A commitment to welfare sentientism may appear to include a commitment to the experience requirement. However, as I will discuss below, this is not necessarily the case. Welfare sentientism is distinct from experientialism (Bernstein 1998), and by itself, much less controversial. Nevertheless, I suggest that if we accept certain basic principles about the coherence between theories of wellbeing and demarcation criteria about welfare subjects, welfare sentientism can provide support for experientialism. Not because extra-experientialist theories are incompatible with welfare sentientism, but because the only way in which they can be made compatible with welfare sentientism is by adding ad hoc constraints to their theories, or adopting views that are otherwise unattractive. Experientialist theories, on the other hand, cohere perfectly with welfare sentientism, in fact, experientialism is able to explain it. In light of the fact that intuitions are so deeply divided on the topic, such coherence should be seen as a significant advantage.

The setup of the article is as follows. Section 2 discusses preliminaries: it introduces the camps, key terms, some of the intuitions that speak in favor and against experientialism, and discusses my methodological commitments. In Sect. 3, I introduce and defend two central premises of the argument: a conception of internal coherence for theories of wellbeing, and the idea of welfare sentientism. Section 4 presents the argument. Section 5 discusses objections. Section 6 briefly concludes.

\section{Experientialism and extra-experientialism}

While experientialism is strongly associated with hedonist theories of wellbeing, endorsing the experience requirement does not necessarily entail hedonism (see Hawkins 2015 for an excellent discussion on this). One may believe, for example, that there are a variety of experiential goods that contribute to someone's wellbeing, such as-besides pleasure-human compassion, a sense of love, a sense of being loved, a sense of discovery, and a sense of comprehension (van der Deijl 2019; Kraut 2018; see also Shepherd 2018). So, while typically extra-experientialist, brute

\footnotetext{
${ }^{3}$ Kagan argues that if we would accept that we are simply our mental states, and the idea that changes in wellbeing require changes in $u s$, then it would follow that only our mental-states count for wellbeing.
} 
list theories can include the experience requirement (see also Woodard 2013). Furthermore, while subjectivism generally is not compatible with the experience requirement, there is an experientialist version of the view, preference-hedonism, which maintains that whatever a person wants to experience is good for that person (Heathwood 2006).

Who are the extra-experientialists? First, one type of theory that is typically extra-experientialist is objective theories, including perfectionism and brute list theories. One reason for this is that, often, objective theories include goods that are not fully experiential, such as achievement, friendship, and knowledge. For example, a friend who talks badly behind the back of their friend is quite plausibly harming their friendship, even if the second person never finds out (see Lauinger 2013). Moreover, perfectionist theories generally believe that the benefit of goods for a person involves actual activity, rather than mere experience. This provides a reason to side with extra-experientialism (e.g. Nussbaum 2008; Badhwar 2014).

Secondly, the most salient adversary of the experience requirement is subjectivist theories of wellbeing-in particular desire-satisfactionism, according to which wellbeing is constituted by the satisfaction of our desires. A satisfaction of a desire involves two things: a desire and the state of the world cohering with that desire. The reason that this view is extra-experiential is that there is no necessary relationship between the satisfaction of a desire and experience. For example, we may want our friends not to talk badly about us behind our back, and we probably want our loved ones not to deceive us. This makes desire-satisfactionism the clearest opponent of the experience requirement. As Dale Dorsey formulates it:

A desire-satisfaction view, unlike preference hedonism, can accept the claim that the boundaries of a person's good are not limited by the boundaries of that person's experience. Call the view that a state of affairs, object, or event $\varphi$ can be a welfare benefit to the person who desires $\varphi$, even if $\varphi$ is never experienced, the "distance allowance". (Dorsey 2013, 155)

As is often the case in controversial debates in philosophy, both sides of the debate are challenged and supported by strong intuitive cases. The most well-known counterexample against desire-satisfactionism comes from Derek Parfit:

"Suppose that I meet some stranger on a train. She describes her life's ambitions, and the hopes and fears with which she views her chances of success. By the end of our journey, my sympathy is aroused, and I strongly want this stranger to succeed. I have this strong desire even though I know that we shall never meet again." $(1984,151)$

The idea that the success of the stranger benefits the protagonist seems strange. Some, but by no means all accounts of wellbeing add a restriction to the domain of desires that can affect wellbeing (see Lukas 2009 for a defense of the unrestricted view). On restricted views, only a subset of desires that are sufficiently close to an individual matter, such as those desires that are "about" a person's own life, or that 
enter a person's experience. ${ }^{4}$ On the other hand, it is intuitive to some that the distance allowance makes space for the wellbeing of someone to be reduced if her friend talks badly of her behind her back, even if she does not find out.

The problem with this ping ponging of inuititions is that 1) not everyone shares them, 2) they point in opposite directions, and 3), as numerous experiments on the experience machine example suggest, the intuitions we have are affected by prudentially irrelevant factors, such as moral considerations, or status quo biases, and are non-trivial to interpret (Weijers 2014; De Brigard 2010; Belshaw 2014; Crisp 2006, 117-125; cf. Lin 2016; Rowland 2017; Hindriks and Douven 2018; see Weijers and Schouten 2013; Bramble 2016; Hawkins 2015).

While one virtue of theories is to fit with as many considered intuitions as possible, another virtue is for theories to be as simple as possible, and to unify a variety of different theoretical considerations. After all, by complicating theoriesthat is, by adding more resources that may help us align intuitions with the core theoretical ideas-meeting intuitions becomes increasingly easier. My suggestion is that while most contemporary wellbeing theories can be made compatible with welfare sentientism, experientialist theories can do so in a way that is able to unify a plausible view about who is a welfare subject with a theory of wellbeing in a much more straightforward way than other theories can.

The argument formulated below attempts to go beyond the mere formulation of intuition pumps and attempts to find some unifying rationale for the experience requirement. Ultimately, of course, the arguments formulated below cannot but build on intuitive support at numerous crucial points in the argument. However, rather than intuitions about constituents of wellbeing directly, I primarily build on intuitions about who is a welfare subject, when we hold certain goods, and when we are benefitted by them.

\section{Welfare sentientism and theoretical coherence}

\subsection{Welfare sentientism}

Do animals have wellbeing? Do fish? Do computers? Being a welfare subject-i.e. having a level of wellbeing-implies that things can go better or worse for you. But, wellbeing is a subset of goodness for (Rosati 2010): things may be good for a nonsentient plant, but this need not imply that it is a welfare subject. Ascribing wellbeing to someone means that things can be good or bad for that subject (e.g. Tiberius 2006), in the sense that things are, or can be, of final value to her. A stone, we can all agree, does not have this property. In case of fish and robots, the question whether this type of goodness applies to them is not obvious. On what grounds can we make this call?

\footnotetext{
${ }^{4}$ Notice that there is a difference with the use of restricted desire in this sense-requiring that desires are about goods that are sufficiently close to us - and the requirement that desires be informed or rational that many desire-satisfactionists subscribe to (see Murphy 1999 for a discussion).
} 
Welfare sentientism is an answer to this question, according to which all and only entities that are sentient are welfare subjects, where sentience is having the capacity to have phenomenological consciousness, i.e. the capacity to have experiences. ${ }^{5}$ Typically, but not necessarily, this includes the ability to feel pain. This implies that there is a moment, at some point in fetus-development, when one becomes sentient, and another moment, close to the time one dies, when one loses it. Welfare sentientism thus excludes certain beings, such as stones, from having welfare, but also limits the welfare of sentient beings in time: only during the time that they are sentient do they possess wellbeing. While welfare sentientism is a highly basic belief, and is therefore difficult to argue for, I briefly provide an argument for why it is plausible.

The wellbeing demarcation question has, interestingly, not attracted much attention in the literature (cf. Lin 2018 who discusses different options; Sumner 1996; and Bernstein 1998 who defend a sentience-account; and Kraut 2009, sect. 2, who rejects welfare sentientism). However, within the literature on moral standing or status, sentience has played a significant role. Within this debate, sentience has been commonly held as a ground for the moral status of animals. While this view comes particularly natural to utilitarians (Singer 1977), sentience as a sufficiency criterion for at least some moral status is much more widely accepted. Consider for example Wayne Sumner's statement of the agreement on this between conflicting views on the moral status of animals: ${ }^{6}$

Both animal welfarists and animal rightists can, and typically do, agree that (1) a creature has moral standing just in case it has interests, (2) having interests requires sentience, or the capacity for experience, and (3) many animals have interests (in this sense) and thus have moral standing. (1988, 164).

The relationship between moral status and wellbeing is not often discussed. Wellbeing and moral status are importantly distinct. While some have argued that non-welfare entities may still be given moral consideration (e.g., contra Sumner, exquisite paintings, forests, or plants, see Goodpaster 1978; Varner 2001; Rodogno 2010), being a welfare subject is generally considered to be sufficient to be granted moral status. The claim that sentience is central to wellbeing is thus weaker than the claim that it is central to moral status. It indeed seems plausible that the reason why we think sentience matters for moral consideration is because we think wellbeing matters for moral consideration. Those who have the ability to experience can have things go better and worse for them, they are subjects of final value, and consequently have moral status. If sentience is indeed a sufficient criterion for moral status because it is sufficient for wellbeing, then this implies that sentience is sufficient for being a welfare subject.

\footnotetext{
5 "Capacity" here, should be understood as the ability to have experiences in a very closely nearby world. The dead are not sentient, even if in some highly-developed technological possible worlds they may be resurrected.

6 This is not to deny, however, that sufficiency conditions for moral status are a topic of significant disagreement, especially if it comes to full moral status (see Jaworska and Tannenbaum 2018).
} 
Is it also necessary? As I suggested above, we typically do not think that stones are welfare subjects. More generally, inanimate objects do not have wellbeing. What other reason could there be for this beside that fact that inanimate objects do not have experiences? To illustrate this, consider a robot-let's call him Robot Pinocchio-who after years of mechanistic functioning develops sentience. Considering non-sentient Robot Pinocchio, we can imagine how things can go better or worse for it in a non-welfare sense: if it stops working, things go badly, and if it is working well without wearing down, we can see how things go well for it. As long as he is not sentient, this goodness for, however, is similar to statements about goodness for that also apply to other use-objects, such as our laptop: it is bad for it to spill water over it, but certainly our laptop is not a welfare subject. Only when Robot Pinocchio starts to experience things can we say that things matter for him, for his sake. If he functions well, it is not only valuable for the person he is serving, but it may start to matter to him too. If that is true, sentience is also necessary for wellbeing.

It is difficult to argue for welfare sentientism on further grounds. Welfare sentientism just seems highly plausible intuitively. In the following, I will build on the claim that welfare sentientism is correct. Nevertheless, I will return briefly to the possibility of it being wrong in Sect. 4.

\subsection{Theoretical coherence}

A theory of wellbeing not only has to answer what wellbeing consists in, but also which entities are welfare subjects, and to which of these wellbeing subjects the theory applies. Thus, we can demand an answer to three questions of any wellbeing theory: 1) what does wellbeing consist in? Wellbeing is constituted by welfare $\operatorname{good}(\mathrm{s}) \mathrm{X}(, \mathrm{Y}, \mathrm{Z}, \ldots)$, and a wellbeing theory states which welfare goods make up the concept of wellbeing. 2) To which entities does this theory apply? We may call this the scope of the theory. And 3), which entities are welfare subjects, and which entities are not? This question may appear to be the same as the second. However, there is a conceptual difference between the scope of the theory and the scope of the wellbeing concept. A theory may only apply to a subset of wellbeing subjects, or may (appear) to cover more entities than just the ones that are welfare subjects.

The question of what the scope of a certain theory is is not fully trivial. However, a welfare good will generally imply that some entities are capable of possessing this good while others are not. Desire-satisfaction, for example, is a good that can only be possessed by those entities that are capable of desire, while having pleasure is only possible for those entities that have the capacity to experience pleasure. These capacities provide what we may call natural demarcation criteria: if a theory states that $\mathrm{X}$ is the only welfare good, this theory applies to all entities capable of holding good $\mathrm{X}$ and only for entities capable of holding this good. For example, if a theory states that desire-satisfaction is the only welfare good, this theory only applies to entities capable of holding desires, but also to all entities that hold desires. Again, 
this is not fully trivial. ${ }^{7} \mathrm{We}$ may, for instance, believe that some entities that are incapable of good X, while X is the only welfare good, simply have welfare level 0 , and cannot be harmed or benefited in any way, until they become capable of possessing good X. Or, we may think that some entities capable of $\mathrm{X}$, perhaps even possessing $\mathrm{X}$, do not have welfare levels after all and are therefore excluded from the scope of the theory. However, if the natural demarcation criteria diverge from the actual scope of the theory, this requires an explanation.

The final question asks what the scope of the concept of wellbeing is. As argued above, welfare sentientism is a plausible answer to this question. These natural demarcations of wellbeing theories may share the following relations with the welfare sentientist criterion:

Perfect coherence: the natural demarcation criterion coheres perfectly with welfare sentientism

Incompleteness: the natural demarcation criterion only applies to a subset of sentient beings.

Overextensiveness: the natural demarcation criterion includes more beings (or entities) than the set of sentient beings.

In the latter two cases, the natural demarcation criteria appear inconsistent with welfare sentientism. After all, in both cases it appears that the set of entities that a theory implies to have wellbeing does not overlap with the set of entities that are welfare subjects according to welfare sentientism. However, this need not be the case. The natural demarcation criteria are only prima facie extensions from the constituents of a theory (question 1) to its scope (question 2), and, there may be a discrepancy between question 2 and 3 . With respect to incompleteness, there are two ways out of the seeming incoherence. Firstly, as suggested above, it may simply imply that all that do not meet the natural demarcation criterion, but are sentient, have zero welfare. More precisely:

Incompleteness implying neutral welfare: the natural demarcation criterion only applies to a subset of sentient beings, while the ones that do not meet the criteria have welfare level 0 .

The plausibility of this solution depends on the particulars of the welfare theory. I will consequently discuss its plausibility when discussing theories to which this may apply.

However, incompleteness may also imply that a theory only applies to a subset of welfare subjects. More precisely:

\footnotetext{
7 It is often taken for granted that such natural demarcation criteria simply follow from the issue of what welfare consists in, and that those simply imply a welfare demarcation criterion (in other words, the answer to question 3 follows from 2, which follows from 1). Sumner (1996), for example, writes "If wellbeing is given the sort of objective interpretation Aristotle suggested, then the class of welfare subjects will embrace all creatures to whom notions such as functioning or flourishing can be meaningfully applied" (74). I agree that this is a natural interpretation, and that a theory has much to explain if it deviates from this logic, but we should acknowledge that relation between the answers to 1, 2, and 3 need not be so straightforward.
} 
Incompleteness implying different welfare theories: the theory of welfare applies to those beings to whom the natural demarcation criterion applies, while some other theory describes the welfare of welfare subjects to whom the criterion does not apply.

This solution, however, faces a more serious problem, because it denies welfare invariabilism: the claim that one theory of welfare applies to all welfare subjects (Lin 2018). In a recent article, Eden Lin provides a convincing argument for welfare invariabilism. Besides its simplicity, Lin argues that the "more important reason to favor invariabilism is that it is difficult, on reflection, to see what could explain why a theory of welfare might be true of some subjects but false of others" $(2018,324)$. And indeed, if welfare is indeed a unified concept, whose significance is similar for different welfare subjects, why would it be constituted differently for different individuals? If it would be, it would be difficult to see why it is nevertheless the same concept.

In case of overextensiveness, there is only one way to make a theory coherent with welfare sentientism, namely, by adding an ad hoc constraint to a theory of welfare:

Overextensiveness implying Ad Hocness: an overextensive theory of welfare is compatible with welfare sentientism by adding the ad hoc criterion that it only applies to sentient beings.

This solution is unattractive for obvious reasons: it implies an ad hoc criterion. One way in which the unattractiveness of ad hoc-ism can take shape is that an overextensive theory that limits itself to sentient beings fails to provide an answer to the following question: If $\mathrm{X}$ constitutes wellbeing, and does not constitute wellbeing in virtue of the experience it provides, why does it only constitute wellbeing for sentient individuals? As long as welfare sentientism does not flow naturally from the theory of welfare, adding a sentience-demarcation criterion will be unable to provide a satisfactory explanation to this question.

\section{Theories of wellbeing and welfare sentientism}

As a first step of the argument, observe that (most) experientialist theories cohere perfectly with welfare sentientism. First, note that no experientialist theory can be overextensive: by definition, experientialism implies that only what can be experienced may contribute to wellbeing, and as non-sentient beings cannot experience, no non-sentient being can have an experientialist welfare good. An experientialist theory may be incomplete. For example, a theory that maintains that only the experience of viewing Rembrandt's The Night Watch is good is strictly speaking experientialist, but is clearly incomplete. Many have led good lives, had positive levels of welfare, suffered or have been harmed without ever having seen The Night Watch. However, most plausible experiential welfare goods are not particular experiences, but determinable properties that apply to all experiences. Most notably, any experience can be evaluated (though perhaps not fully evaluated) 
on a hedonic scale. This is not to say that all experiences are either pleasurable (enjoyable) or painful (contain suffering). Some experiences may be hedonically neutral, or anhedonic. But an anhedonic experience is a rather neutral good. So, a hedonist would, not implausibly, describe an entity that has such experiences as a welfare subject with neutral welfare. An experientialist who believes other features of experiences also contribute to wellbeing would have tools available to ascribe non-neutral welfare values even to such anhedonic experiences. Most importantly, however, since any experience can at least be evaluated in hedonic terms, any experientialist theory that includes hedonic levels as a welfare good will also not be incomplete. So, any experientialist theory that includes general determinable properties like hedonic properties as one welfare good, will cohere perfectly with welfare sentientism. ${ }^{8}$

As discussed in Sect. 2, extra-experientialist theories of wellbeing can take a number of shapes. In order to see to what extent extra-experientialism is compatible with welfare sentientism, I review desire-satisfactionism, perfectionist theories, brute list theories, and a number of goods that typically make it on (extraexperientialist) brute lists: friendship, knowledge, and achievement, and finally I discuss hybrid theories that give experiential goods a central role.

\subsection{Desire-satisfaction is incomplete}

The nature of desire is a controversial subject, but at least on some plausible conceptions of desire, desires necessarily involve a certain phenomenology (see Schroeder 2006 for an overview). If that is true, in order to have desires, one needs to be sentient. However, a first problem for the compatibility of welfare sentientism and desire-satisfactionism is that while all desirers may be sentient, not all sentient beings are necessarily desirers. Any particular suggestion can be controversial, but it seems plausible that late-stage fetuses are sentient but lack desires, and that earthworms and simple fish may be sentient but lack desires (see, for example, Dorsey 2017, 692, ft. 10 for a similar claim). About this category of beings, desiresatisfactionism simply does not have anything to say. Consequently, desiresatisfactionism is incomplete: if welfare sentientism and desire-satisfactionism are both true, it would be puzzling why desire-satisfactionism only applies to a subset of welfare individuals.

As discussed above, there may be two solutions to incompleteness. First, we may simply conclude that for all beings that are not desirers, but are sentient, welfare levels are zero. This, however, would be deeply implausible. If a sentient fetus is physically hurt and feels pain, this is not good for her, and the same goes for any other non-desiring sentient being.

Alternatively, we may simply posit that a different theory, perhaps a hedonistic theory, applies to these creatures, while desire-satisfactionism applies to desirers. This would violate welfare invariabilism, and create a significant burden of

\footnotetext{
${ }^{8}$ For simplicity, I will not make this qualification when I mention experientialist theories in the remainder.
} 
explanation on the part of the desire-satisfactionist. But, what's more, for creatures like sentient fetuses-creatures that do not have desires yet, but will get desires in the near futures-this implies an odd welfare dynamic (Lin 2017): if welfare hedonism is true of fetuses, but as soon as fetuses or babies start having desires desire-satisfactionism becomes true, wellbeing may start making odd leaps. For instance, if our first desires are not satisfied, a baby's wellbeing level may drop from a sufficient level to a very low level by gaining the ability to desire. As Lin argues, this is odd, and difficult to rationalize.

\subsection{Desire-satisfactionism is overextensive}

There is a further problem for desire-satisfactionist accounts. While desires may necessarily be formed by sentient beings, the same does not hold for the satisfaction of desires. In fact, we may hold numerous desires for things that will, or can, only be satisfied after we die: the success of the lives of our children, how our will is executed, or recognition for our life's work. When we hold a desire for our will to be executed in the way we intended, and this actually occurs, a desire is satisfied.

We may say that executing a friend's will successfully will benefit the friend posthumously. This would appear to violate welfare sentientism-as the dead are no longer sentient. So, while the first problem poses an incompleteness problem for desire-satisfactionism and welfare sentientism, this problem shows that desiresatisfactionism may also be overextensive. In response, the desire-satisfactionist could exclude the satisfaction of desires that are satisfied posthumously. This would eliminate the overextensiveness problem, but would be ad hoc (see Parfit 1984, 495, for a similar argument). Recall that desire-satisfationism typically makes space for extra-experiential benefits-what Dorsey has called the "distance allowance". If desire-satisfaction allows for disbenefit through frustrated desires that never enter one's experience in general, it is difficult to see what is so special about death such that desires about posthumous events cannot affect a person's wellbeing. ${ }^{9}$

In response, a desire-satisfactionist can point out that we have assumed that when a desire is satisfied posthumously, the benefit must also take place posthumously. As plausible as this may seem, recently Dorsey (2013) and Bruckner (2013) have defended the view that the benefit of posthumous satisfaction of desires occurs during a person's lifetime (see also Pitcher 1984; Luper 2004). ${ }^{10}$ On this view, posthumous desire-satisfaction benefits a person at the time an event that occurs

\footnotetext{
9 As an anonymous referee pointed out, some desire-satisfaction theories maintain that in order for a person to benefit from desire-satisfaction, a person must still hold the desire at the time it is satisfied (Heathwood 2005, 490). Dorsey (2013) discusses this view, and calls it "concurrentism". I believe he successfully argues against this idea. Most significantly, he argues that it creates an unwarranted asymmetry between temporal and spatial distance: "Because [concurrentism] allows spatial distance between the desirer's experiences and that which benefits the desirer (insofar as one needn't experience, at the time it is good for one, the satisfaction of a desire), a refusal to allow temporal distance would appear to place unwarranted evaluative significance in the fact that the relevant "distance" is in the now." (2013, 157-58 [emphasis in the original]).

10 See (Callahan 1987), Taylor (2005), and Portmore (2007) for critical perspectives on the idea that we can be benefitted or harmed posthumously.
} 
posthumously is desired by the living desirer. This would mean that posthumous acknowledgment of a person's work is good for that person when that person is desiring that they will be acknowledged for their work. This would help make desire-satisfaction compatible with welfare sentientism. After all, it would not imply that welfare goods are held by non-sentient (dead) individuals. While this solution seems highly counter-intuitive to me, I grant that foot-stompingly denying its plausibility is not a fruitful way to tackle this position (though cf. Portmore 2007). ${ }^{11}$ Rather, I point out two implications of this view that strongly speak against it.

A frequently raised objection against this view is that it implies backward causation-events in the future cause wellbeing states now-and consequently, is deeply implausible as a general feature of value. However, as Donald Bruckner (2013) has argued, this need not be the case. The events at time $t_{1}$ are not affected by $t_{2}$, only their value for the person having the desire is: "This is not backward causation, but merely waiting to see how things turn out" (26). However, granting that this solution does not involve physical backward causation, it does imply a backward determination of wellbeing value (Scarre 2012 suggests "backward significance"): how good a particular moment is now, may be determined by future events. This has two problematic implications in the context of posthumous harm and benefit.

First, it seems plausible to think that all value can, in principle, be appreciated, that is, recognized, experienced, or perceived as good. However, if Bruckner and Dorsey's suggestion is correct, there are substantial categories of wellbeing value that cannot possibly be appreciated in this way. If I have a desire that gets satisfied posthumously, and I have not told anyone about this desire, this creates a value for me that neither I, nor anyone else, could possibly recognize as such. For example, I may wish that my funeral is well-attended, but that uncle Derek does not come, because I secretly hold a grudge against uncle Derek. If uncle Derek indeed does not come, who could appreciate the value that this has created for me? The problem here is not so much that the value is not appreciated, because, in part, this may be what is at stake in the debate between experientialism and extra-experientialism. However, the problem is that it could not possibly be appreciated: the welfare subject is dead, and no one else knows of the existence of the desire that is satisfied. This gives the value a metaphysically mysterious character: if the purported value of a good cannot possibly be appreciated by anyone, why would we think it has value?

Second, the solution proves too much. As long as someone has future-directed desires, then their wellbeing is undetermined until the future has determined these desires satisfied or frustrated, or the success achieved or not. This may seem plausible for things that occur at our funerals, but if we accept that our desiresatisfaction about our funeral may make a difference to us during our lifetime, then we must also think that any desire that is satisfied (or frustrated) posthumously still

\footnotetext{
11 Portmore writes: "[This view] is implausible. It implies that you are in a harmed condition right now if you currently desire that your remains will be cremated when, in fact, they will not be. And this implication stands even if the reason your remains will not be cremated is that you will eventually change your mind and, in the end, charge the executor of your will with donating your corpse to medical science. (...) These implications are absurd, and so we should reject [this] View." (30).
} 
plays a role in determining our lifetime wellbeing. For example, if Julius Caesar held a desire for posthumous recognition, then what is being said about Caesar during history classes (and whether he is discussed at all) still affects Caesar's wellbeing. His wellbeing during his life thus still fluctuates based on the memory, recognition and appreciation of him by people today. This becomes particularly mind-boggling when people hold desires for the continued existence of the human race: if people hold these desires, a person's wellbeing only becomes determined by the death of the last human. After all, the satisfaction of this desire only becomes determined once it is frustrated, and humans no longer exist. This means that ultimately, a person's wellbeing is practically never determined. The question What is the degree of Nathan's wellbeing? is not answerable, at least as long as Nathan has desires that still extend into the future. There is a well-known ancient Greek saying: "call no man happy, until he is dead". ${ }^{12}$ This may have some plausibility. However, the view that the satisfaction of desires contributes to wellbeing at the time the desire is held would imply that no person's life can be called good until their last desire has been satisfied or frustrated. That seems to be an absurd stretch.

If these considerations are convincing, then posthumous desire-satisfaction cannot affect wellbeing during a person's lifetime, and if it does, it must do so after someone dies, at which time, a person is no longer sentient. Consequently, posthumous desire satisfaction creates an overextensiveness problem for desiresatisfactionism.

\subsection{Flourishing accounts}

According to perfectionist, or flourishing, accounts of wellbeing, wellbeing consists in a number of irreducible goods that are connected in that they all contribute to the exercise of a person's natural capacities, or the fulfilment of her nature. The problem for perfectionist accounts is that they are overextensive. There are some entities that have natures that can be fulfilled without having sentience. Most plausibly, most plants are like this: a plant can function in accordance with its nature, even though plants are probably not sentient. ${ }^{13}$ If welfare sentientism is correct, the explanandum for flourishing accounts is the fact that there are many more entities that can flourish than there are entities that are sentient. Why, if flourishing is what ultimately matters to wellbeing, would it only matter to sentient beings? Plants, even if they are non-sentient, can flourish.

This question has received some attention in the related discussion about moral status. Nussbaum (2009), for example, discusses a version of this challenge in the context of moral consideration, in which she seems to doubt the sentience of mosquitoes:

It seems minimally bad to kill a mosquito, because it appears that a mosquito does not feel pain. It is easy for Singer [as a utilitarian] to explain this

\footnotetext{
12 This saying is often ascribed to Solon.

13 Plant sentience is admittedly a controversial subject. Andrew Smith (2016, chap. 2) presents an interesting case for the sentience of plants. However, the defense remains highly speculative..
} 
conclusion; it is more difficult for the capabilities theorist to do so, since the good resides in opportunities for flourishing, not in sentience alone (2009, 361).

Nussbaum agrees with the intuitive appeal of the utilitarian demarcation. Nevertheless, she believes that sentience is not a necessary condition, but rather one among a number of sufficient conditions for moral consideration. Nussbaum's claim concerns a different target-the moral status of beings, rather than their wellbeing. Nevertheless, it illustrates the tension between the significance we attach to sentience and flourishing accounts of wellbeing.

If flourishing constitutes wellbeing, and welfare sentientism is correct, flourishing accounts need to explain why the flourishing of non-sentient entities does not constitute wellbeing for them, even though it does constitute wellbeing for sentient beings. Within the flourishing axiology, such a constraint does not appear to have any rationale. Above, I have suggested that the only solution to overextensiveness is to adopt an ad hoc restriction on whom the theory applies to-namely, flourishing only matters for sentient beings. This is unsatisfactory though. How can limiting wellbeing to sentient beings be compatible with an account of flourishing in which experience does not play any role? Perfectionist accounts seem to have no resources available to satisfactory answer this question.

\subsection{Brute list theories}

Brute list theories are theories of wellbeing that are pluralistic, but, different from desire-satisfaction and perfectionist accounts, not unified by a general principle. Their pluralist axiology allows experiential goods to be listed. Consequently, it is not the case that experience plays no role in their axiology. Any brute list that contains an experiential good (such as pleasure) as one item on the list is able to explain why all sentient beings are welfare subjects, as all are capable of having good or bad experiences. Any such list thus avoids the incompleteness concern. However, brute list theories would face similar problems as flourishing accounts of wellbeing if they contain items that apply to non-sentient beings. Whether they do depends on the list. We can look at a number of the most promising and common candidates: knowledge, achievement, and friendship.

A first problem for the coherence between welfare sentientism and these goods is that it is unclear whether sentience itself is required to obtain them. Consider Chalmers's (1996) philosophical zombie. The philosophical zombie is able to do most of the same things that others can: for example, they can go to university, drive cars, and be in romantic relationships. However, they lack phenomenal experience. They are, in other words, not sentient. However, if Chalmer is right, it is unclear that his zombie cannot have knowledge-after all, the zombie is able to finish his university exams)—; achieve certain things—for all we know, Einstein may have 
been a zombie; or maintain friendships ${ }^{14}$ - his friends, after all, would not realize he is a zombie. If that is true, the coherence problem for brute list theories is clear: nonsentient entities hold welfare goods.

However, there is a further problem, which is similar in shape to the problem that faced desire-satisfactionism. In order to see this, we need to look at the different goods in turn.

First, consider friendship. Even if sentience is necessary for the formation of friendships, it is not obvious that the same applies to the holding of friendships. In particular, consider the question whether friendships survive death. There are different possible answers. A first is to suggest that it does. This seems intuitive, as we generally say that a funeral is visited by the friends of the deceased, not by their former friends. However, if so, it is clear that friendship is a good that presents an overextensiveness problem: if we keep our friends after death, the deceased have a welfare good. So, it will have to be explained why the deceased have no welfare, even though they do have a welfare good.

A second answer is to deny that friendships survive death, even though friendship is an extra-experiential good. This also seems to be a reasonable suggestion. This would solve the tension between the good of friendship and welfare sentientism: no dead, and thus non-sentient, beings would have friends. However, this solution gives too much significance to death in friendship, especially if we can think of the good of friendship as extra-experiential. Given that we usually think we can benefit from friendship even when we are apart from our friends and cannot experience one another's companionship, it is not clear why death (another way of being apart) would end friendships. To see this, consider an example: a friend, Elizabeth, talks badly about another friend, Emma. As some extra-experientialists may believe, this by itself may harm Emma. Imagine that this happens at 12:41 on a Thursday afternoon. Now, as it turns out, Emma dies at 12:39. If that is true, on this view, Elizabeth's gossip did not disbenefit the second friend after all, as it occurred after Emma's death. But this seems odd. The harming of the friendship seems very similar in case the second friend would die at 12:45, 12:55, or 21:00, and it seems difficult to see why it would harm someone in these cases, but not in case a person dies at 12:39.

Another suggestion is to claim that friendship only benefits us when we experience the companionship of friendship, or think about our friends in some positive way. This would explain why only sentient beings can benefit from friendship, but this would turn friendship into an experiential good. So, if we want to see friendship as valuable in an extra-experientialist way, we would have to be committed to the view that friendships may benefit or disbenefit us after we die, and consequently, be overextentive with respect to welfare sentientism.

Now, consider achievements. As Gwen Bradford suggests "achievements are characterized by a process-product structure: all achievements have a process,

\footnotetext{
14 In the context of robot love, there is a lively philosophical discussion on the question whether nonsentient robots are capable of love, and whether mere loving behavior is sufficient for this (see Hauskeller 2016; and Levy 2009 for two different views)..
} 
which culminates in a product" (Bradford 2013, 205) ${ }^{15}$ On her view, achievements are more valuable when they are more difficult, or have a more valuable product, which can be further explained by the human capacity to exercise her will. ${ }^{16}$ While the exercise of effort and will (to overcome difficulty) may be possible only for sentient beings, the product of achievement may be achieved long after the individuals who have exercised their efforts have died (and stopped being sentient). If the product of an achievement contributes to its value, the achievement of this product must contribute to a person's wellbeing long after they have died.

Consider, for example, the time and effort invested by a diplomat, who aims to achieve global cooperation on a significant goal—such as the reduction of pollution. She successfully brings together a number of international congresses, but none are successful. She dies, and, inspired by a letter she wrote on her deathbed, the international community comes together and signs the agreement the diplomat has always dreamed of. This achievement is obtained posthumously, so it certainly seems the achievement is achieved by someone who is no longer sentient.

Again, defenders of the wellbeing value of achievements have two moves available. First, they may claim that achievements only contribute to a person's wellbeing if that person is alive to see the product. This would keep the compatibility of welfare sentientism with this value. However, it would be difficult to see what the rationale for this move would be without reducing the value of achievement to the value of the experience of achievement, in other words, reducing achievement to an experiential value.

Second, they may claim that posthumous achievement contributes to a person's wellbeing, while that person is alive. This parallels the move of the desiresatisfaction theorist who claims that posthumous satisfied desires contribute to a person's wellbeing at the moment she is desiring them. The problems it faces are therefore also the same: it entails that our wellbeing may be undetermined for very long stretches of time after we die (if ever), and it may imply principally unappreciatable value if people pursue private projects that no one knows about, but that nevertheless are achieved posthumously.

Finally, knowledge. Knowledge is extra-experiential because while beliefs are (plausibly) mental states, knowledge consists of a relation between this mental state and the world. Given a certain belief content (that X), the difference between knowledge (true belief that $\mathrm{X}$ ) and false belief need not register in our experience in any way. For example, we may believe that our teenage child is quietly reading in their room, while they in fact have sneaked out to go to a friend's party. Such situations may also occur about future-oriented beliefs. For example, I may believe that my children will have a bright future. When I pass away, and this belief is then determined to have been true, we end up with a similar problem as with friendship,

\footnotetext{
15 In particular, what is significant about achievements is that they are different from attaining goals, or desires, because an achievement necessarily results from the efforts of the achiever (Keller 2004, 33; Portmore 2006, 3).

${ }^{16}$ Bradford explicitly states that she intends her account to be an account of value of achievements in general, not of the contribution achievement has to wellbeing. However, for an account of wellbeing, the concept of the value of achievement would have to be similar.
} 
achievement, and desire-satisfaction: either I hold the good of knowledge at the moment it is determined to be true, but this would imply I have a welfare good when I am no longer sentient; or we can maintain that it benefitted me while I was still alive, leading to similar problems as before: a person with future oriented beliefs will have an undetermined level of wellbeing for long after they die, and if these beliefs are held privately, they are principally unappreciatable.

\subsection{Alternatives and hybrids}

So far, I have argued that desire-satisfactionism faces a problem of incompleteness. And, all extra-experiential welfare goods that we have discussed face a common problem: overextensiveness. This latter problem can be generalized as follows:

(1) On extra-experientialist accounts of wellbeing, welfare goods may affect our welfare without entering into our experience

(2) For an extra-experientialist theory that contains such a good, $\mathrm{X}$, these theories either allow that $\mathrm{X}$ can be had by non-sentient beings or that $\mathrm{X}$ can be had by sentient beings after death (when sentience is gone).

(3) In order to be coherent with welfare sentientism, theories that are overextensive must either adopt an ad hoc constraint, or require backward determination.

(4) Neither of these moves is a satisfactory response to the dilemma.

So far, I have focused on extra-experientialist goods that are commonly included in philosophical theories of welfare. To what extent is this argument generalizable to all welfare goods? There is no guarantee that this argument will apply to all extraexperientialist goods, however, it is difficult to think of extra-experientialist goods to which it does not apply.

As a final example, I discuss how this argument even applies to experientialistextra-experientialist hybrids that maintain that good experiences, such as enjoyment, are necessary for wellbeing, but take the value of this enjoyment to rely on (possible) relational factors. A prominent example is (Sumner 1996, ch.6) authentic happiness account of wellbeing according to which wellbeing is identical to life-satisfaction (or, happiness) except if the life-satisfaction is unauthentic, that is, when it is based on standards that are not autonomously formed, or based on false information that, if it were to come out, would affect a person's evaluation of her life given a person's own set of priorities. This view is extra-experiential. To use Sumner's own example, a businessman may be happy because he has a happy marriage and successful business, not knowing that his wife is having an affair behind his back, and his business partner will betray him. According to Sumner, these latter facts make him worse off, even though he does not experience them. At the same time, though, Sumner's view has a natural connection with sentience, and appears to fit well with welfare sentientism. In fact, it may even explain the necessity of sentience for being a welfare subject. ${ }^{17}$

\footnotetext{
17 Though not its sufficiency: many non-sentient beings may not have the required autonomy to have authentic happiness.
} 
However, again, the same argumentative pattern applies: our degree of authentic happiness may change posthumously. While we are alive, we may be happy in light of expectations we have about the future, such as my children having a bright future in front of them after I die. Our happiness about this may turn out to be inauthentic (the future of our children is not bright after all). ${ }^{18}$ This again, implies that a significant part of my wellbeing would be determined after my death, creating the possibility of principally unappreciable welfare value. For example, I may take satisfaction in the posthumous appreciation of my colleagues, that only becomes authentic when it actually occurs posthumously. If this is problematic in the case of desire-satisfactionism, then it would also be problematic for theories that suggest that the wellbeing value of happiness depends on relational properties that may be determined after we die. ${ }^{19}$

\subsection{Taking stock}

We can now fully articulate the sentience argument for experientialism. A first central premise of the argument is that all and only sentient beings are welfare subjects. A second is that there should be a certain coherence between the question "Who is a welfare subject?" and "What constitutes wellbeing?". In principle we should expect a theory that maintains that wellbeing consists in $\mathrm{X}$ to also maintain that all beings that have good $\mathrm{X}$ are welfare subjects. And if that theory states that wellbeing only consist in X, the welfare of all welfare subjects is described by X. In case of experientialist theories, this coherence holds perfectly if welfare sentientism is true. For other theories, this is not clear. First, theories that do not contain experiential goods-such as desire-satisfactionism, are incomplete. They can only describe the welfare of a subset of all welfare subjects. Second, extra-experiential theories are typically over-extensive. While these theories may be coherent with welfare sentientism, in order to be coherent, they either need to exclude certain entities that hold wellbeing goods in an ad hoc fashion, or they need to postulate a very particular way in which external circumstances affect our wellbeing, namely, that future circumstances affect our wellbeing today. The first is unattractive for obvious reasons, while the latter is unattractive because it has implausible implications. This is, to be sure, not a knock-down argument against these theories.

\footnotetext{
${ }^{18}$ It is important to note that Sumner himself is skeptical about the possibility of posthumous welfare changes. In discussing desire-satisfactionism (which he calls "the desire theory", and its implications for posthumous welfare changes, he writes: "Some people find it just obvious that the dead can be neither benefitted nor harmed, while others find it equally obvious that lives are capable retroactive prudential improvement. I confess that I belong to the former camp. Dying has precious few consolations, but surely one of them is that beyond that threshold we are safe from any further misfortunes" (Sumner 1996, 127). Sumner does not (as far as I know) discuss the implications of his own view for cases in which someone takes satisfaction in expectations about events that may occur after they die. Given his comments about desire-satisfactionism, it is unlikely that he would accept that in such cases a person's welfare could be affected. However, it is not clear on what grounds he would make such a claim..

19 Another view to which this objection applies is the view that wellbeing consists in enjoyment of the good (Kagan 2009). This position faces similar problems, as people can take enjoyments in goods whose goodness will only be fully determined after one dies, such as contributing to a work of art that will only be finished by others after one dies..
} 
However, it should count in favor of experientialist theories that they are able to answer the two central questions-"Who is a welfare subject?" and "What constitutes wellbeing?"-in a simple and unifying way, without having to make such unattractive postulations.

\section{Objections}

There are two objections that deserve some attention.

\subsection{Denying welfare sentientism}

First, welfare sentientism may be denied. If so, the argument above would have little traction. At the same time, the case for welfare sentientism has been mostly intuitive. While I do not know what grounds someone may have for denying it, I acknowledge that people may do so, even though it would seem highly counterintuitive to either ascribe wellbeing to non-sentient entities, or to deny that some sentient entities are welfare subjects. What can be said to them? To those in doubt about its plausibility, the argument may still provide a conditional argument: if welfare sentientism is correct, this would provide a strong argument in favor of experientialism. Because welfare sentientism seems to have at least some plausibility, the argument provides in the very least, some support for experientialism.

\subsection{Denying that coherence matters}

An alternative way to resist the argument is to deny that the two types of coherence that I have employed in the argument and defended in Sect. 3-invariabilism and avoiding ad hoc-ism — should be desiderata for theories of wellbeing. One may think that ad hocism is a perfectly acceptable response in order to align our independent concern about who is a welfare subject and what wellbeing consists in. Similarly, one may think that it is perfectly fine to postulate a variety of wellbeing theories that describe the constituents of wellbeing for different categories of welfare subjects.

The reason we value theoretical coherence, or theoretical simplicity more broadly, is a fundamental issue, which goes far beyond the scope of the article. However, I can point to a pragmatic reason for considering the importance of theoretical coherence in the context of the philosophical debate about the nature of wellbeing. As discussed in Sect. 2, our intuitions about wellbeing are unlikely to resolve the controversies in the debate about the nature of wellbeing. They vary strongly between individuals, and are often difficult to rationalize. Wellbeing theories are consequently underdetermined by the intuitions that we have. If we allow our theories to be ad hoc or incomplete, this will only make it easier for theories to fit a large set of intuitions, resulting in further possibilities for divergence. 


\section{Conclusion}

The experience requirement is a topic that strongly divides intuitions. On the one hand, we may strongly feel that if we don't experience something it could not possibly affect how good our lives are for us, that "ignorance is bliss", and that "what we can't know can't hurt us". On the other hand, we may strongly feel that talking badly behind someone's back harms that person. The question whether wellbeing abides by the experience requirement or not is one that is not likely to be settled by our direct intuitions about extra-experiential goods, as our intuitions on this issue conflict, and are not very stable. In this article, I have presented an argument in favor of experientialism. If we believe that a theory of wellbeing owes us an answer to the question who is a welfare subject, and that we may expect a coherence between the answer to this question and the constituents of wellbeing it proposes, then welfare sentientism counts strongly in favor of experientialist theories of wellbeing. To formulate the argument in a positive fashion: an experientialist theory of wellbeing is not only attractive on its own accord, but, different from extra-experientialist alternatives, it provides a clear answer to the question "Who is a welfare subject?" that fits perfectly with our pre-theoretical intuitions.

Acknowledgements I would like to thank Mauro Rossi, Nathan Wildman, Paul Boswell, Huub Brouwer, and Philippe Verreault-Julien for helpful discussions on the argument made in this article. Moreover, an anonymous referee of this journal has also been exceptionally helpful in improving the paper. I have presented previous versions of this paper at Wellbeing, Happiness, and the Good Life conference at the Centre de recherche en Ethique in May 2019, the Midi d'ethique at the Centre de Reserche en Ethique in spring 2018, and at the OZSW conference, Enschede 2018. I am grateful for the audience for helpful comments, in particular to those of Peter Dietsch, Christine Tappolet, Angie Pepper, Valéry Giroux, and Rich Healey.

Open Access This article is licensed under a Creative Commons Attribution 4.0 International License, which permits use, sharing, adaptation, distribution and reproduction in any medium or format, as long as you give appropriate credit to the original author(s) and the source, provide a link to the Creative Commons licence, and indicate if changes were made. The images or other third party material in this article are included in the article's Creative Commons licence, unless indicated otherwise in a credit line to the material. If material is not included in the article's Creative Commons licence and your intended use is not permitted by statutory regulation or exceeds the permitted use, you will need to obtain permission directly from the copyright holder. To view a copy of this licence, visit http:// creativecommons.org/licenses/by/4.0/.

\section{References}

Badhwar, N. K. (2014). Well-being: Happiness in a worthwhile life. Oxford: Oxford University Press. Belshaw, C. (2014). What's wrong with the experience machine? European Journal of Philosophy, 22(4), 573-592. https://doi.org/10.1111/j.1468-0378.2011.00507.x.

Bernstein, M. (1998). Well-Being. American Philosophical Quarterly, 35(1), 39-55.

Bradford, G. (2013). The value of achievements. Pacific Philosophical Quarterly, 94(2), 204-224.

Bramble, B. (2016). The experience machine. Philosophy Compass, 11(3), 136-145.

Bruckner, D. W. (2013). Present desire satisfaction and past well-being. Australasian Journal of Philosophy, 91(1), 15-29. https://doi.org/10.1080/00048402.2011.632016. 
Callahan, J. C. (1987). On harming the dead. Ethics, 97(2), 341-352.

Chalmers, D. J. (1996). The conscious mind: In search of a fundamental theory. Oxford: Oxford University Press.

Crisp, R. (2006). Reasons and the good. Oxford: Oxford University Press on Demand.

De Brigard, F. (2010). If you like it, does it matter if it's real? Philosophical Psychology, 23(1), $43-57$.

Dorsey, D. (2013). Desire-satisfaction and welfare as temporal. Ethical Theory and Moral Practice, 16(1), 151-171. https://doi.org/10.1007/s10677-011-9315-6.

Dorsey, D. (2017). Why should welfare 'Fit'? The Philosophical Quarterly, 67(269), 685-708.

Goodpaster, K. E. (1978). On being morally considerable. The Journal of Philosophy, 75(6), 308-325.

Hauskeller, M. (2016). “Automatic Sweethearts.”. In M. Hauskeller (Ed.), Mythologies of transhumanism (pp. 181-199). Cham: Springer. https://doi.org/10.1007/978-3-319-39741-2_10.

Hawkins, J. (2015). "The experience machine and the experience requirement”. In G. Fletcher (Ed.), The Routledge handbook of philosophy of well-being (pp. 371-381). London and New York: Routledge.

Haybron, D. M. (2005). On being happy or unhappy. Philosophy and Phenomenological Research, 71(2), 287-317.

Heathwood, C. (2005). The problem of defective desires. Australasian Journal of Philosophy, 83(4), 487-504.

Heathwood, C. (2006). Desire satisfactionism and hedonism. Philosophical Studies, 128(3), 539-563.

Hindriks, F., \& Douven, I. (2018). Nozick's experience machine: An empirical study. Philosophical Psychology, 31(2), 278-298. https://doi.org/10.1080/09515089.2017.1406600.

Jaworska, A., \& Tannenbaum, J. (2018). The grounds of moral status. In E. N. Zalta (Ed.), The stanford encyclopedia of philosophy. Metaphysics Research Lab, Stanford University. Retrieved January 2020 from https://plato.stanford.edu/archives/spr2018/entries/grounds-moral-status/.

Kagan, S. (1992). The limits of well-being. Social Philosophy and Policy, 9(2), 169-189.

Kagan, S. (2009). Well-being as enjoying the good. Philosophical Perspectives, 23(1), 253-272. https:// doi.org/10.1111/j.1520-8583.2009.00170.x.

Keller, S. (2004). Welfare and the achievement of goals. Philosophical Studies, 121(1), $27-41$.

Kraut, R. (2009). What is good and why: The ethics of well-being. Cambridge: Harvard University Press.

Kraut, R. (2018). The quality of life: Aristotle revised. Oxford: Oxford University Press.

Lauinger, W. A. (2013). The strong-tie requirement and objective-list theories of well-being. Ethical Theory and Moral Practice, 16(5), 953-968.

Levy, D. (2009). Love and sex with robots: The evolution of human-robot relationships. New York: Harper Collins.

Lin, E. (2016). How to use the experience machine. Utilitas, 28(3), 314-332. https://doi.org/10.1017/ S0953820815000424.

Lin, Eden. (2017). Against welfare subjectivism. Nô̂s, 51(2), 354-377.

Lin, E. (2018). Welfare invariabilism. Ethics, 128(2), 320-345. https://doi.org/10.1086/694272.

Lukas, M. (2009). desire satisfactionism and the problem of irrelevant desires. Journal of Ethics and Social Philosophy, 4, 1-24.

Luper, S. (2004). Posthumous harm. American Philosophical Quarterly, 41(1), 63-72.

Murphy, M. C. (1999). The simple desire-fulfillment theory. Nô̂s, 33(2), 247-272. https://doi.org/10. 1111/0029-4624.00153.

Nozick, R. (1974). Anarchy, state, and utopia. New York: Basic books.

Nussbaum, M. C. (2008). Who is the happy warrior? philosophy poses questions to psychology. The Journal of Legal Studies, 37(S2), S81-S113.

Nussbaum, M. C. (2009). Frontiers of justice: disability, nationality, species membership. Cambridge: Harvard University Press.

Parfit, Derek. (1984). Reasons and Persons. Oxford: Oxford University Press.

Pitcher, G. (1984). The misfortunes of the dead. American Philosophical Quarterly, 21(2), 183-188.

Portmore, D. W. (2006). Welfare, achievement, and self-sacrifice. Journal of Ethics and Social Philosophy, 2, i.

Portmore, D. W. (2007). Desire fulfillment and posthumous harm. American Philosophical Quarterly, 44(1), 27-38.

Rodogno, R. (2010). Sentientism, wellbeing, and environmentalism. Journal of Applied Philosophy, 27(1), 84-99. https://doi.org/10.1111/j.1468-5930.2009.00475.x.

Rosati, C. S. (2010). Relational good and the multiplicity problem1. Philosophical Issues, 19(1), 205-234. https://doi.org/10.1111/j.1533-6077.2009.00167.x. 
Rowland, R. (2017). Our intuitions about the experience machine. Journal of Ethics and Social Philosophy, 12, 110.

Scarre, G. (2012). Speaking of the dead. Mortality, 17(1), 36-50.

Schroeder, T. (2006). Desire. Philosophy Compass, 1(6), 631-639.

Shepherd, J. (2018). Consciousness and moral status. Abingdon: Routledge.

Singer, P. (1977). Animal liberation. New York: A discus book discus book. Avon books.

Smith, A. F. (2016). A critique of the moral defense of vegetarianism. Berlin: Springer.

Sumner, L. W. (1988). Animal welfare and animal rights. The Journal of Medicine and Philosophy: A Forum for Bioethics and Philosophy of Medicine, 13(2), 159-175. https://doi.org/10.1093/jmp/13.2. 159.

Sumner, L. W. (1996). Welfare, happiness, and ethics. Oxford: Clarendon Press.

Taylor, J. S. (2005). The myth of posthumous harm. American Philosophical Quarterly, 42(4), 311-322.

Tiberius, V. (2006). Well-being: Psychological research for philosophers. Philosophy Compass, 1(5), 493-505. https://doi.org/10.1111/j.1747-9991.2006.00038.x.

van der Deijl, W. J. A. (2019). Is pleasure all that is good about experience? Philosophical Studies, 176(7), 1769-1787.

Varner, G. (2001). Sentientism. In D. Jamieson (Ed.), A companion to environmental philosophy (pp. 192-203). Oxford: Blackwell.

Weijers, D. (2014). Nozick's experience machine is dead, long live the experience machine! Philosophical Psychology, 27(4), 513-535.

Weijers, D., \& Schouten, V. (2013). An assessment of recent responses to the experience machine objection to hedonism. Journal of Value Inquiry, 2(9), 461-482.

Woodard, C. (2013). Classifying theories of welfare. Philosophical Studies, 165(3), 787-803.

Publisher's Note Springer Nature remains neutral with regard to jurisdictional claims in published maps and institutional affiliations. 